\title{
REPÚBLICA POPULAR DA CHINA: EVOLUÇÃO E ADEQUAÇÃO DO ORDENAMENTO JURÍDICO CHINÊS AOS DIREITOS HUMANOS
}

Vitor Eduardo Tavares de Oliveira*

\section{Resumo}

O presente artigo tem como objetivo analisar e questionar os aspectos legais, no âmbito do ordenamento jurídico e constitucional da República Popular da China, especificamente no que tange à evolução dos direitos humanos naquele país. Dessa maneira, o objeto de estudo restringe-se ao campo dos direitos e garantias fundamentais, com foco na concepção dos direitos coletivos em detrimento dos direitos individuais preconizados pela cultura ocidental. Finalmente, por esse trabalho, demonstrar-se-á como se efetiva a influência internacional no fomento dos direitos humanos na China e como o pensamento confuciano pode corroborar para o desenvolvimento dos direitos humanos mundiais.

Palavras-chave: República Popular da China. Direitos e garantias fundamentais. Direitos humanos. Confúcio.

\section{Introdução}

Tendo em vista a proeminência da República Popular da China no atual contexto global, torna-se valorosa a análise dos aspectos jurídicos e constitucionais acerca da evolução dos direitos humanos no ordenamento jurídico chinês.

O Direito chinês surgiu há mais de quatro mil anos, durante a dinastia Xia, a primeira dinastia da história da China. Porém, até o século

\footnotetext{
* Acadêmico do $6^{\circ}$ semestre do curso de Direito - UNICEUB
} 
XIX, a idéia central na resolução de conflitos sociais era a de "conciliação", procurando sempre o bom senso. Esse modo de encarar os litígios provocados por desavenças sociais concedeu ao direito aspecto de menor relevância.

Observam-se, na cultura jurídica chinesa, a educação e a persuasão posicionadas em primeiro plano, enquanto a autoridade e a coerção estão delegadas a planos inferiores. David, entretanto, assinala que "a solução dada deve, em qualquer ocasião, ser conforme, independentemente de um esquema jurídico, à eqüidade e ao sentimento de humanidade” (DAVID, 2002, p. 593).

A ciência do direito nunca foi de grande importância na vida chinesa, verificando-se que não se encontram nomes de juristas famosos na constituição histórica do povo chinês.

Por esse entendimento, faz-se necessário relatar a parte histórica da República Popular da China que possui, aproximadamente, cinqüenta e sete anos de existência, sendo uma das civilizações mais antigas do globo.

Segundo Abi-Sad (1996, p. 138):

A tradição chinesa desdobrou-se em um mundo fechado, que recusava a presença e o contato com o estrangeiro e que para o ocidente era tema das incríveis narrativas de Marco Pólo. Tratava-se de um universo chinês reflexo de circunstâncias que transcendia mera expressão de síntese geopolítica.

Podemos apontar como marco importante na história chinesa "O Grande Salto Adiante", que constituiu a adoção de planos de política e de economia diferenciados da ex-União Soviética. Nesse contexto, o papel do Direito, na vida do povo chinês, obteve essencial mudança, principalmente, a partir do implemento do Estado Socialista. 
De acordo com Mezzetti (2000, p. 33):

Mao convocou uma segunda sessão no oitavo congresso, fazendo repudiar os planos econômicos, aprovados anteriormente, e aprovando em seu lugar outros, mais grandiosos, sob a égide do slogan de mobilizar todas as energias, mirar ao alto, construir um socialismo melhor, mais velozmente e a menor custo.

Assim, com a efetivação do referido regime e com a influência soviética no Estado chinês, verificam-se algumas medidas legislativas e jurídicas nunca antes tomadas pelo sistema político chinês.

\section{Constituição chinesa}

Na formação do Estado Socialista, o líder chinês Mao-TséTung inspirou-se no confucionismo. A teoria confucionista da lealdade à família foi redirecionada para a lealdade ao Partido Comunista Chinês (PCC) e ao Estado. Dessa forma, o ideal confucionista de virtude, sob o ponto de vista do pensamento maoísta, era o apoio irrestrito ao programa político, jurídico e econômico do PCC e à sua prática.

Desde a fundação de sua República Popular, em 1949, a China adotou quatro Constituições (1954, 1975, 1978 e 1982).

No tocante à Constituição vigente, apontamos as quatro partes que a compõem, dando ênfase, precipuamente, à segunda, que trata dos direitos fundamentais e dos deveres do cidadão.

A constituição de 138 artigos se divide em quatro capítulos. Disposto (sic) no primeiro capítulo Princípios Gerais estão as questões do sistema político e econômico da República Popular da China, bem como sua política social. No segundo capítulo, aborda Direitos Fundamentais e Deveres dos Cidadãos. Segue-se (sic), no terceiro capítulo, informações referentes à Estrutura do Estado, por fim, capítulo que trata da Bandeira Nacional, Emblemas e a Capital do País. (1982) (NORONHA; MCNAUGHTON; PANGA, 2002, p. 43). 
É necessário analisar o ordenamento constitucional e infraconstitucional, sempre tendo em vista a implantação e a efetivação dos direitos humanos, pois tal estudo possibilitará o entendimento da concepção dos chineses perante as leis e de seus litígios diante do Poder Judiciário.

O sistema de resolução de controvérsias, na sociedade chinesa, coloca a conciliação em destaque, em detrimento do direito, o qual é posto como uma função subordinada. Isso pelo fato da grande influência do confucionismo no pensamento chinês.

Proclama-o o próprio Mao-Tsé-Tung num discurso proferido em 27 de fevereiro de 1957: o direito não se faz para todo mundo. Dois métodos, segundo os casos, apropriados para resolver as contradições que se produzem na sociedade. Um destes métodos é o que apela para o direito e para suas sanções: é o método da ditadura. Considerava-se bom para os "bárbaros"; atualmente reserva-se sua aplicação para os contrarevolucionários (DAVID, 2002, p. 597).

Atualmente, a República Popular da China é regida pela Constituição de 4 de dezembro de 1982, que já sofreu algumas modificações para melhor atender aos anseios do Estado socialista. Além do preâmbulo, como já foi mencionado anteriormente, a constituição possui quatro partes: Capítulo I - Princípios Gerais, Capítulo II - Direitos e Deveres fundamentais do cidadão, Capítulo III - Estrutura do Estado e Capítulo IV - Bandeira Nacional, armas e capital.

Na análise de Godoy:

O preâmbulo da constituição chinesa insiste na edificação do socialismo deve ser feita por meio do apoio da classe trabalhadora, dos camponeses e dos intelectuais [...] Prevê-se que a República Popular da China seja um Estado multinacional unitário, cuja criação dependeu da associação das diversas nacionalidades que convivem no país (GODOY, 2006, p. 238).

Na constituição de 1982, lê-se o seguinte: 
Art. $1^{\circ}$ - A República Popular da China é um Estado socialista de ditadura democrática popular, dirigida pela classe trabalhadora e baseada em aliança entre operários e camponeses. O sistema socialista é o sistema básico da República Popular da China. É proibida a sabotagem do sistema do sistema socialista por qualquer organização ou indivíduo (REPÚBLICA POPULAR DA CHINA, 1987, p. 5).

Observa-se, pois, que o Estado chinês descreve, no primeiro artigo da Constituição, o seu sistema político e econômico e veda qualquer interferência no sistema em questão, o que deixa claro, já de início, a importância do Estado naquele país.

Segundo Arnaud:

Após 1978, [...] aráveis de aspirações democráticas, de uma exigência de abertura, de críticas à censura e à repressão, de esperança de quebrar o monopólio do poder detido pelo Partido, de realizar uma descentralização político cultural e de edificar o Estado no qual tanto o governo quanto o povo sejam obrigados a respeitar a lei e, mais especificamente, os direitos humanos, e a manter um mínino de legalidade (ARNAUD, 2000, p. 382).

\section{Legislação infraconstitucional}

Cumpre assinalar, inicialmente, que a legislação infraconstitucional é, em boa parte, recente. Nesse sentido, destaca-se, sobre o ordenamento jurídico chinês: a legislação aduaneira, de 1987, que regula o sistema aduaneiro chinês; a lei de arbitragem promulgada em 1994, a qual diz respeito às questões contratuais relacionadas ao direito de propriedade; também a legislação trabalhista adotada em 1994, que dispõe sobre normas de tutela de trabalho, contratos de trabalho e contratos coletivos, jornada de trabalho, descanso e férias, remuneração, normas de segurança, entre outras questões pertinentes; além da legislação que trata da regulamentação do acesso à internet, de 1996. 
Percebe-se, pelo exposto, que o crescente número de leis, adotadas recentemente pelo Estado Chinês, demonstram uma maior preocupação desse país com a preservação dos direitos de seus cidadãos, protegendo, ainda mais, os direitos inerentes à pessoa.

\section{Solução de conflitos}

Na China, existem mais de 200.000 comissões populares de mediação, nas quais atuam semi-oficiais, que resolvem milhões de litígios. Contudo, não apenas as comissões possuem a função de resolver litígios. Muitos deles são resolvidos por sindicatos, comissão de rua, células do partido e outros órgãos de caráter administrativo. Esse sistema lembra os juizados especiais que existem no Brasil, mas, na China, tais órgãos possuem caráter administrativo.

Os processos são raros e, normalmente, movem-se contra os depravados, incorrigíveis e os inimigos do povo.

David (2002, p. 595) afirma que

As sanções do direito não devem ser aplicadas àqueles que, apesar das suas possíveis faltas, continuam a ser bons cidadãos. O princípio da legalidade socialista, ao qual o direito havia parecido, numa certa época, querer ligar-se, é abandonado. O direito é o último remédio para os casos em que os outros modos de solução de litígio tenham excepcionalmente falhado.

A partir da promulgação da Constituição chinesa de 1978, ocorreu um forte movimento legislativo, o que permitiu a criação de várias leis com intuito de evitar injustiças que os líderes de hoje sofreram ou viram na revolução cultural. Além disso, esse movimento pretende o contrário do pregado na política anterior, oferecendo garantias aos estrangeiros, principalmente ocidentais, para que haja investimento na China.

\section{Influência internacional}


O ordenamento jurídico chinês sofreu modificações, recentemente, no sentido de implantar e efetivar os direitos humanos, com vistas a atender aos seus anseios econômicos e às cobranças internacionais.

Com a entrada da China, há pouco tempo, na Organização Mundial do Comércio, o Estado chinês teve de seguir três princípios:

1. oferecer privilégios a todos os membros, de acordo com o princípio da nação mais favorecida;

2. conceder tratamento nacional a importações; e

3. mostrar transparência com relação às leis e aos regulamentos que exigem cumprimento.

Nota-se que o último preceito, juntamente com o movimento legislativo vivenciado pela China, mostra um caráter de maior preocupação com a função do direito quanto ao crescimento da nação chinesa.

O princípio da legalidade ainda não tem, para o chinês, a mesma importância que tem para os cidadãos ocidentais. Porém, evidencia-se uma evolução nesse sentido, a partir da primeira Constituição, em 1954, e diante da realidade atual. Podemos constatar tal mudança com o enriquecimento do ordenamento jurídico chinês por inúmeras leis relativamente recentes.

Não obstante, a China ainda necessita ampliar o judiciário com um número maior de juízes, de advogados e de tribunais. Além disso, também, faz-se necessário eliminar, por completo, sua hostilidade perante as leis e o direito.

\section{Direitos humanos}

A Constituição Chinesa de 1982 já garante a liberdade de religião, de expressão e de reunião; entretanto, esses direitos são bastante 
limitados. Em 2004, após aprovar uma emenda constitucional, a Constituição chinesa passou a proteger os direitos humanos, pela primeira vez, em seu aspecto constitucional e jurídico. Mas é pouco provável que a medida abra a porta para a liberdade plena de expressão. Nesse sentido, pronuncia-se Xiaobo em matéria da Reuters (Pequim):

'O conceito de direitos humanos ainda é muito vago na China', disse Liu Xiaobo, crítico literário e dissidente preso após os protestos pró-democracia da Praça Tiananmen, em 1989. 'O problema mais básico é que o respeito e a proteção que o Estado garante aos direitos humanos entra (sic) em conflito com o sistema de governo unipartidário, no cerne da Constituição', afirmou (AGÊNCIA REUTERS, 2006).

Para Nicolas Becquelin, tal fato é

um sinal importante de que a China aderiu, ou foi convencida a aderir, ao conceito e à linguagem dos direitos humanos". Ele vê isso como "um grande incentivo de legitimidade às pessoas que vêm trabalhando para proteger os direitos dos cidadãos chineses" e acrescenta, ainda, que "a emenda pode ser precursora de mudanças (AGÊNCIA REUTERS, 2006).

Diferentemente do que acontece com a Constituição americana, são raros os casos de advogados, na China, que já tentaram evocar a Constituição para respaldar seus argumentos num tribunal. O objetivo da Constituição é criar diretrizes amplas. Algumas leis chinesas [assim como ocorre com as leis brasileiras] chegam a contrariar a Carta.

A China insiste que direitos humanos fundamentais significam alimentar, vestir e alojar seu 1,3 bilhão de habitantes e que os direitos individuais devem ficar em segundo plano. Mas as reclamações sobre direitos humanos constituem uma espinha permanente nas relações externas (AGÊNCIA REUTERS, 2006).

Verifica-se, com a afirmativa acima, certa dificuldade de reconhecer os direitos humanos com a mesma ótica ocidental, tendo em vista 
a concepção que prima mais pelo direito coletivo do que pelo direito individual.

A República Chinesa vem impulsionando a construção da democracia e da legalidade e melhorando o status quo dos direitos humanos, em virtude, principalmente, da pressão da sociedade internacional. Tal fato demonstra preocupação e atenção à implementação e à efetividade dos direitos humanos na República Popular da China.

Vale ressaltar que o pensamento confuciano pode muito contribuir para enriquecimento dos direitos humanos ocidentais provenientes do pensamento iluminista do século XVIII. Tu Weiming¹ (apud BALDI, 2004, p. 364) esclarece:

A crítica ao individualismo ganancioso, à competitividade danosa, ao relativismo pernicioso, à postura excessivamente contenciosa, nos ajuda a entender que os valores do iluminismo não foram necessariamente um guia integrado para a ação. O conflito entre liberdade e igualdade e a falta de preocupação com a comunidade é capaz de solapar em muito o poder de persuasão dos direitos humanos baseados exclusivamente no interesse próprio de indivíduos isolados. Os valores confucianos, como idéias sólidas sobre a prosperidade humana, podem servir de fonte de inspiração para representar os direitos humanos como linguagem comum da humanidade.

A soma dos Direitos Humanos, no contexto global, com o pensamento confucionista poderá ajudar a humanidade no desenvolvimento do princípio da fraternidade para melhor implementar esses direitos na atual sociedade globalizada.

De acordo com Bobbio (1992, p. 1),

${ }^{1}$ Diretor do Harvard-Yenching Institute, nasceu em Kunming (China). Desde 1981, é professor de história chinesa e filosofia na Universidade de Harvard 
O reconhecimento e a proteção dos direitos do homem estão na base das Constituições democráticas modernas. A paz, por sua vez, é o pressuposto necessário para o reconhecimento e a efetiva proteção dos direitos do homem em cada Estado e no sistema internacional. Ao mesmo tempo, o processo de democratização do sistema internacional, que é o caminho obrigatório para a busca do ideal da 'paz perpétua', no sentido kantiano da expressão, não pode avançar sem uma gradativa ampliação do reconhecimento e da proteção dos direitos do homem, acima de cada.

\section{Conclusão}

A República Popular da China tem muito a desenvolver no âmbito do direito. Esse país precisa, ainda, acostumar-se com essa ciência, para que os direitos humanos, sua mais nobre expressão, possam beneficiar os cidadãos chineses.

Nas palavras de Tu Weiming (apud BALDI, 2004, p. 370),

os valores confucianos revividos não são uma representação fundamentalista de idéias nativistas; eles são, como um todo, valores tradicionais transformados, compatíveis e comparáveis com o principal ímpeto da ideologia moderna definida em termos de idéias iluministas.

Em suma, além dos pontos apresentados, deve-se destacar que é de fundamental importância não apenas criticar a maneira como os chineses vivem e demonstrar como devem viver, mas, também, aprender com a cultura chinesa de forma que ela promova a evolução e adequação dos direitos humanos em todo o globo. O ocidente vive e cultua o individualismo exacerbado, e, talvez, o pensamento confuciano, que promove a fraternidade, possa mudar os paradigmas e aperfeiçoar os direitos humanos universais.

\section{Chinese Law and Human Rights}

\section{Abstract}


The present article has as objective analyzes, to investigate and to conflict the legal aspects in what plays to the juridical and constitutional ordinance of the Popular Republic of China. It will be looked for to restrict the mark of the work in the ambit of the rights and fundamental warranties focusing the conception of the collective rights in detriment of the individual rights extolled by the western culture. Finally it will be demonstrated the international influence in the fomentation of the human rights in China and as the Confucian thought it can corroborate for the development of the world human rights.

Keywords: Popular Republic of China. Fundamental Rights and Warranties. Human Rights. Confucio.

\section{Referências}

ARNAUD, André-Jean. Introdução à análise sociológica do sistema jurídico. Rio de Janeiro: Renovar, 2000.

ABI-SAD, Sergio Caldas. A potência do dragão: a estratégia diplomática da China. Brasília:UNB, 1996.

AGÊNCIA REUTERS. China inclui direitos humanos em sua Constituição. Disponível em: <http://www1.folha.uol.com.br/folha/reuters/ ult112u32552. shtml>. Acesso em: 16 out. 2006.

BALDI, César Augusto. Direitos humanos na sociedade cosmopolita. Rio de Janeiro: Renovar, 2004.

BOBBIO, Norberto. A era dos direitos. Rio de Janeiro: Campus, 1992.

CANÇADO TRINDADE, Antonio Augusto. Tratados de direito internacional dos direitos humanos. Porto Alegre: S. A. Fabris, 1999. v. 1.

CANÇADO TRINDADE, Antonio Augusto. Tratados de direito internacional dos direitos humanos. Porto Alegre: S. A. Fabris, 1999. v. 2.

CANÇADO TRINDADE, Antonio Augusto; PEYTRIGNET, Ruiz de Santiago. As três vertentes da proteção internacional dos direitos da pessoa 
humana. San José; Brasília: Instituto Interamericano de Direitos Humanos, Comitê Internacional da Cruz Vermelha, Alto Comissariado das Nações Unidas para refugiados, 1996.

CHEVIRIER, Yves. Mao e a Revolução Chinesa. São Paulo: Ática, 1996.

CHINA ONLINE. Disponível em: <http://www.chinaonline.com.br/>. Acesso em: 21 abril 2005.

CHINA.ORG.CN. Disponível em: <http://www.china.org.cn/english/index. htm>. Acesso em: 21 abril 2005.

DAVID, René. Os grandes sistemas do direito contemporâneo. São Paulo: M. Fontes, 2002.

GARAUDY, Roger. O problema chinês. Rio de Janeiro: J. Zahar, 1968.

GODOY, Arnaldo Sampaio de Moraes. Direito constitucional comparado. Porto Alegre: S. A. Fabris, 2006.

GOMES Canotilho, José Joaquim. Estudos sobre direitos fundamentais. Coimbra: Coimbra, 2004.

HASBAERT, Rogério. China entre o oriente e o ocidente. São Paulo: Ática, 1999.

LENG, Shao-Chuan. Justice in communist China. [S.l.]: Oceana, 1967.

LIN, Fu-Shun (Org.). Chinese law past and present: a bibliography of enactments and commentaries in English text. [S.l.: s.n.], 1966.

LIMA; PEREIRA; CABRAL. China 50 anos de república popular. São Paulo: Anita Garibaldi, 1999.

MEZZETTI, Fernando. De Mao a Deng: a transformação da China. Brasília: UnB, 2000.

MORAES, Alexandre. Direitos humanos fundamentais: teoria geral. São Paulo: Atlas, 2003.

NORONHA; MCNAUGHTON; PANGA. A China pós OMC: direito e comércio. São Paulo: Observador Legal, 2002. 
PINHEIRO, GUIMARÃES. Direitos humanos no século XXI. Brasília: Senado Federal; IPRI, 2002. parte 2.

PIOVESAN, Flavia. Temas de direitos humanos. [S.l.]: Max Limonad, 1999.

PIOVESAN, Flavia. Direitos humanos e o direito constitucional internacional. [S.l.]: Max Limonad, 2002.

POMAR, Wladimir. Revolução chinesa. São Paulo: Unesp, 2003.

REPÚBLICA POPULAR DA CHINA. Constituição da República Popular da China. Rio de Janeiro: Edições Trabalhistas, 1987.

SPENCE, Jonathan D. Em busca da China moderna. São Paulo: Companhia das Letras, 1996.

TSIEN, T. Les institutions chinoise et la Constitution de 1978. [S.l.: s.n.], 1979. 